\title{
1 MARINE DEBRIS OCCURRENCE AND TREATMENT: A REVIEW
}

Iñiguez, M.E.; Conesa*, J.A.; Fullana, A. Chemical Engineering Department. University of Alicante. P.O. Box 99, 03080 Alicante (Spain). Phone: +(34) 965903867 Fax: +(34) 965903826

* Corresponding author email: ja.conesa@ua.es

\section{Abstract}

Marine debris produces a wide variety of negative environmental, economic, safety, health and cultural impacts. Most marine litter has a very low decomposition rate (as plastics, which are the most abundant type of marine debris), leading to a gradual, but significant accumulation in the coastal and marine environment. Along that time, marine debris is a significant source of chemical contaminants to the marine environment. Once extracted from the water, incineration is the method most widely used to treat marine debris. Other treatment methods have been tested, but they still need some improvement and so far have only been used in some countries. Several extraction and collection programs have been carried out. However, as marine debris keep entering the sea, these programs result insufficient and the problem of marine debris will continue its increase. The present work addresses the environmental impact and social aspects of the marine debris, with a review of the state of the art in the treatments of this kind of waste, together with an estimation of the worldwide occurrence and characteristics.

\section{Introduction}

"Marine litter is defined as any persistent, manufactured or processed solid material discarded, disposed or abandoned in the marine and coastal environment" [1, 2]. It consists of items that have been made or used by people and deliberately discarded into the sea or rivers or on beaches; brought indirectly to the sea with rivers, sewage, storm water or winds; 
accidentally lost, including material lost at sea in bad weather (fishing gear, cargo); or deliberately left by people on beaches and shores [3].

The presence of marine debris is a cause for concern due to several reasons. It is known to be harmful to organisms and to human health $[1,4-6]$, it has potential to increase the transport of organic and inorganic contaminants [7-11], it presents a hazard to shipping, and it is aesthetically detrimental, and thus generating negative socio-economic consequences [12].

Litter can easily be mistaken as food by animals and cause health complications or even death. Many studies have investigated the ingestion of plastic items by marine animals, including fish [13], cetaceans [14], turtles [15] or seabirds [16, 17]. Fishing gear can become ocean pollutant as a result of accidental losses or dumping. Entanglement in abandoned fishing gear is another important threat not only for marine mammals [18, 19], but also for benthic biota [20].

The economic impact of marine debris is noticeable. At beaches, marine debris causes aesthetic problems, especially in touristic areas where they generally lead to a decline in tourist traffic and oblige the concerned municipalities to substantial cleaning costs. At sea, floating marine debris endanger the maritime traffic. Small items can block propellers and collisions are always possible with larger debris. In addition, litters trapped by fishing nets is becoming a recurring issue for fishermen [21]. A diagram that represents the lifecycle of marine debris is shown in Figure 1 (adapted from [22]): the produced plastic discards are accumulated during a period of time in the beaches and float or are washed to the seabed by water columns, suffering a fragmentation. The fate of the plastic is then its collection (via more encouraging), its decomposition (that will last hundreds of years) or ingestion by marine organisms. From this figure, it is important to note that the startup of new policies managing the discards is the only practical route for combating marine litter problem. 
The material most commonly found in marine debris are glass, metal, paper and plastic

51 (OSPAR, 2007), and, according to the publish literature, it is clearly apparent that, globally,

52 plastic items are consistently the most abundant type of marine debris [3, 23-26].

\subsection{Plastics in marine debris}

54

Plastics are synthetic organic polymers that are malleable and can be molded into solid objects of diverse shapes. In addition, they are strong, lightweight, durable and inexpensive [27], properties that make them suitable for the manufacture of a wide range of products.

The main reason why plastics are hazardous to the marine environment is their resistance to degradation. The natural decomposition of plastic items in the sea occurs in an exceedingly long time, usually estimated between hundreds and thousands of years [28], therefore, plastics accumulate in the marine environment and persist for decades [29]. Chemical contaminants such as polychlorinated biphenyls (PCBs) and dioxins are released into the sea during this degradation. Furthermore, plastic items are fragmented into small pieces, becoming plastic micro-particles (with a diameter of less than $5 \mathrm{~mm}$ ) [30], which are ingested by animals, thus being very harmful to marine life [31, 32].

Plastics have existed only for around a century [33], but since the development of the plastics industry, plastic products are the most abundant around the globe, hence representing $60-80 \%$ of the total marine debris [34]. A compilation on the proportion of plastics found in the marine debris was done 15 years ago [4]. Table 1 presents new data on the same subject published from then. An average value of $>65 \%$ of plastics in the rubbish is found, denoting the importance of controlling the plastic deposition in all places around marine environment, such harbors, beaches, and those from the fishing and recreational activity.

[Table 1]

\subsection{Composition of the plastic marine debris}

The most commonly used plastics are Polyethylene, Polypropylene and polyethylene terephthalate, therefore, they are the most frequently found in the marine environment too [35- 
37]. Table 2 presents the data found in literature about the distribution of different types of plastics in the marine litter collected. It is important to note the very important and unexpected amounts of cellulose acetate (CA) used in cigarette filter manufacture that has been signaled as a very important problem in oceans.

\section{[Table 2]}

\section{Quantities of collected marine debris}

Until the 1970s, there were no scientific texts speaking about ocean pollution by plastic waste. More than forty years later, still there is not any accurate estimation of the amount of this residues present in the marine environment.

It is not possible to know the exact route of entry of these debris (rivers, air, pleasure craft, fishing or merchant ...). The estimated amount of these debris found in specific rivers ranging from less than $1 \mathrm{~kg}$ per day (Hilo, Hawaii) to 4,200 kg per day (Danube) [38, 39]. Most of marine debris entering the sea ends up accumulating on the seabeds (70\%), and the rest remains on the shores (15\%) and in the water columns (15\%) [40].

Recent studies have shown that the amount of debris accumulated in the marine environment depends of the location, characteristics of the area, and the season of the year, especially when precipitations are strong and river flows are higher [41-43]. Depending of topography, rocky shore lines contain the most of the debris, followed by sandy beaches; and regarding to the season, the biggest density of debris has been found in autumn, and the lowest in spring [44].

\subsection{General marine debris}

There are very few studies focusing on the total amount of marine debris accumulated in the seas and oceans around the world [45]. Forty years ago, it was estimated that the total amount of debris accumulated in the oceans every year was around 6,360,000 tons [46].

In recent years, several initiatives have been carried out by various organizations for the collection of marine debris in different coastal areas. One of the most significant studies 
worldwide was "The UNEP Global Initiative on Marine Litter", a cooperative activity of UNEP/GPA and the Regional Seas Program (RSP). In this project it was carried out the collection of marine debris of twelve Regional Seas: Baltic Sea, Black Sea, Caspian, East Asian Seas, Eastern Africa, Mediterranean, Northeast Atlantic, Northwest Pacific, Red Sea and Gulf of Aden, South Asian Seas, Southeast Pacific, and Wider Caribbean, between 1989 and 2007. The total debris items collected were 103,247,609 [3].

Other similar projects are focused only in specific areas. At the surface of the Mediterranean Sea were estimated from 1.2 to 2000 items per $\mathrm{km}^{2}$ [47]. The amount of marine debris located on sandy beaches, rocky shores and in coastal waters of the Coastal System of Coquimbo between summer 2002 and autumn 2005 were 6,906, 1,149 and 267 items, respectively. [48]. In 2003 and 2004, 54-94 items per $\mathrm{km}^{2}$ of marine debris were recollected in the Pacific coast of northern Japan. In 2011, due to the Tohoku earthquake and tsunami, 233232 items per $\mathrm{km}^{2}$ were quantified [49]. The abundance of marine debris observed during transects in the Straits of Malacca and Bay of Bengal during May-June 2012 was 17,740 and 18,211 items, respectively [50]. In 2012, in South Korea, 42,595 tons of marine debris were collected from coasts, water column and seabeds. [45]. During the winter in 2013, the abundance of marine debris were investigated in the Western Indian Ocean on remote Alphonse Island, where a total of 4,743 items from $1 \mathrm{~km}$ of windward beach were removed [51, 52].

\subsection{Plastic debris}

Plastics can be found in a lot of products (shopping bags, food packaging, facial cleansers, household items...). The global annual production of plastics is around 280 million tons [53, 54]. Recent surveys estimate that between 4.8 and 12.7 million tons of plastic waste ends up in the world's oceans every year [55].

In a recent study [55] the waste estimates for the top 20 countries mismanaging plastic wastes is presented. These 20 countries or regions accumulate $83 \%$ of mismanaged plastic waste that could end up in the ocean. Among the 20 most polluting countries, China is the first 
one, USA is the number 20 and the EU as a whole is located in the number 18. Therefore, it is estimated that the reduction of this waste by $50 \%$ would result in a decrease of around $40 \%$ of the plastic inputs to the ocean.

The 192 countries with coast in the Atlantic, Pacific, Indian, Mediterranean and the Black Sea generated 2,500 million tons of solid waste in 2010, of which 270 million were plastic waste. Coastal areas generated 99.5 million tons of plastic waste, of which 31.9 million were mismanaged waste, i.e., more than $30 \%$. Of these, around 8 million tons entered the ocean in $2010[55]$.

The annual input of plastics in the oceans increases every year. It is estimated that in 2015 around 9.1 million tons will be accumulated. By 2025, the annual input of plastics to the sea would be about double what it was in 2010. By then, the total amount of plastic debris accumulated in the oceans around the world is estimated around 155 million tons [55].

\section{Extraction and disposal of marine debris}

Marine debris is collected mostly by boats. Usually, each port has a waste manager which is responsible for collecting the waste generated by both, port facilities and boats. The amount collected depends on the fishing activity in the area and is not uniform.

Every year, various programs for Coastal Cleanup are carried out, in which a large amount of marine debris are collected from various coastal areas by numerous volunteers, but this is not enough. Over recent years, Korea has carried out a program for removal and collection of marine debris, which seems insufficient, but may shed some light on the problems of ocean pollution.

\subsection{Floating marine debris}

The Korean coast is bursting of floating and submerged marine debris [56]. Most of the waste that ends up in the worldwide oceans is transported by rivers or water canals. In order to prevent this, a floating debris containment boom has been developed. 
This containment mechanism used by Korea in order to prevent marine debris to end up in the ocean consist on a floating portion that is located on both sides of a plate, they have a streamlined shape and are made of reinforced polystyrene foam compressed to reduce the hydrodynamic force of residues colliding on it. From the bottom there is a net, in order to prevent the passage of any object that, due to the current, can be in the water column. Later, from a bulldozer located on a boat, the marine debris accumulated in the containment barrier are collected. The other end of the barrier is connected to a large float which is tied with a string to the seabed. The installation of the barrier in the right place is very important to assure an effective operation, bearing in mind that, due to the current, floating debris accumulates between the boat and the containment barrier.

Every year, this barrier is installed during the season of heavy rain, when around 1300 tons are collected, representing around $10 \%$ of the total marine debris recovered. In addition to this process, several programs of cleaning and collection of marine debris are carried out in the Korean coast [57].

\subsection{Marine debris accumulated in the seabed}

\subsubsection{Probing equipment}

In many shallow coastal waters, exploration on the seafloor were carried out by two divers with snorkel towed behind a small boat [58]. On depths of $100 \mathrm{~m}$, a side scan sonar (SSS) was used together with a bottom trawl net [59-62]. For greater depths, between 50 and $2700 \mathrm{~m}$, manned submersibles were used [59].

An equipment called "Tow-Sled" suitable for drilling in the seas, with moderate depths (between 500-1000 m) has been developed in Korea. It is a kind of sleigh equipped with lights, cameras and long-range acoustic positioning system, which provides information on the amount, type and location of marine debris. This system is attached to the boat with a steel cable, and moves towed by it thanks to two skates solder on each side of the equipment base [63]. 

depends on where the operation is going to take place, as it could be a rocky or sandy area. Marine debris collection was carried out by a crane located on a boat with interchangeable hooks, which may be curved to prevent debris slide or articulated to narrow rocky. This method is operated in Korea around 130-150 days a year, and collects about 350 tons of marine debris annually.

\section{Pollutants contained in the marine debris}

Persistent organic pollutants (POPs) such as polychlorinated biphenyls (PCBs) and organochlorine pesticides are present in aquatic systems worldwide as a consequence of their wide-spread usage, long-range transport, and persistence. Individual POPs have characteristic patterns of distribution depending on regional patterns of usage and their physico-chemical properties. An international group of research units are trying to monitor the POPs contamination worldwide, by using beached plastic resin pellets [64]. This scheme, International Pellet Watch, has been in operation since 2006.

Other studies have been also reported the importance of the amounts of pollutants contained in the different marine environment. Table 3 presents some results of the most relevant studies performed in the last decade. PCBs, heptaclorocyclohexanes (HCHs), dichlorodiphenyltrichloroethanes (DDTs) and poly-aromatic hydrocarbons (PAHs) are considered, as they have been found in different media. As can be seen in this Table, an important amount of POPs can be found in the plastic pellets, which can aggravate the effects of intake of them by the marine fauna. Average values found in literature would give approximately $45 \mathrm{ng}$ PCBs/g, $5 \mathrm{ng} \mathrm{HCHs/g,} 20 \mathrm{ng}$ DDTs/g and $2500 \mathrm{ng}$ PAHs/g-pellet. Of particular concern is the case of the high levels of DDTs found in the California beaches as well as the high values of PAHs in all studies found. Nevertheless, the concentrations are highly variable between the samples, and more research is needed in this sense. organic chemicals [65-68], pointing out the necessity for new policies contemplating this important problem. 


\section{Marine debris treatment}

210 Marine debris, once removed from the sea, is removed by an incineration process. This 211 process is the most commonly used for processing the marine debris. However, over recent 212 years, projects of treatment and recovery of this debris, such as recycling or fuel production 213 have been carried out.

\subsection{Pre-treatment}

The pre-treatment process is very important, independently on how such debris are treated thereafter, since marine debris contains salt and other contaminants. This process includes: sorting, cutting, separating lead, grinding and cleaning of salts and sludge. The cleaning process ensures mechanical stability, reduce the sodium content and other salts, and improve the quality of the material. The method used, type and sequence of the pre-treatment steps varies based on the main process for the treatment of this waste.

\subsection{Treatments}

\subsubsection{Fuel production from marine debris (RDF)}

Marine debris has high calorific value $(4000-6700 \mathrm{kcal} / \mathrm{kg})$. This feature makes it suitable for using as fuel. The analysis of the physical properties of refused-derived fuel (RDF) show that marine debris contains a high percentage of carbon and hydrogen $(\mathrm{C}: 73.58 \%, \mathrm{H}: 6.304 \%, \mathrm{~N}$ : $0.338 \%$, S: $0.391 \%$, others: $19.387 \%)$. Most of this debris are plastics, which can be transformed into RDF.

There is an RDF production plant that was developed in 2000 as a pilot plant. This facility included a pre-treatment process, had a capacity of $50 \mathrm{~kg} / \mathrm{h}$ of debris and extruded solid fuel. The process had several steps: grinding, water cleaning, dryer, silo and injection molding extrusion [56]. The RDF obtained could be used also as a raw material in the recycling industries for manufacturing of new plastic items.

\subsubsection{Marine debris recycling}


Most of the marine debris, such as different types of plastics, can be recycled and used as raw materials in the production of other items. The production process for these items would be the same as with the virgin materials, but requiring a cleaning stage for removing salts.

Polystyrene buoys are the most widespread waste in the aquaculture industry. To reduce and recycle this type of debris, a volume reduction system has been developed. This system is able to process $100 \mathrm{~kg} / \mathrm{h}$ of waste buoys and recover raw material suitable for the production of recycled items. The process includes several steps: separation of embedded organisms, grinding, salts and sludge cleaning, drying, storage and molding injection. Twenty one local governments in Korea, where there is a large volume of marine debris, have thermal extrusion facilities for polystyrene buoys currently in operation. Between 40 and 80 tons of this waste are treated each year by each one of these installations. In addition, there are small portable systems that can be carried on trucks. These system is able to process $30 \mathrm{~kg} / \mathrm{h}$, and have been developed to treat buoys discarded at remote places [56].

The fiberglass reinforced plastic (FRP) vessels are another remarkable type of waste in the aquaculture industry. In 1980, 65,000 vessels were built with this material. The lifecycle of this vessels is 25 years, which are normally abandoned on harbors, shores and rivers [69]. In 2008, a pilot direct melting system was developed, which was able to process $30 \mathrm{~kg} / \mathrm{h}$ of this type of waste. The capacity of this system is going to be upgraded to process $150 \mathrm{~kg} / \mathrm{h}$, around 1000 vessels per year or up to 2 tons per plant [63].

\subsubsection{Incineration of marine debris}

Pyrolysis and combustion have always been considered as attractive alternatives for waste disposal, since these techniques provide a reduction in volume of waste and also involve profitable energetic and/or chemical products. Thermal decomposition of waste can take place both in controlled conditions (incinerators, cement kilns...) and non-controlled conditions, for example, during fires or open-air burning. The substances emitted during non-controlled plastic thermal degradation may create a serious hazard for human health and for the environment. 
Some marine debris cannot be recycled or reused. On most countries, incineration is the most widely used process to treat marine debris. In this process, the production of air pollutants requires special attention, since incomplete combustion of these can generate harmful gases. Furthermore, due to chlorine, generation of dioxins in this process is important and must be measured

Until now plastic fractions of marine debris have been landfilled because it was considered as a waste product with low value; however, today it is known that this waste has a great value and it is suitable for recycling, mainly by chemical or energy recovery, especially attractive for polyolefin waste [70].

Thermal treatment of chlorinated wastes it is a problematic way of recovery. Besides hydrogen chloride, chlorinated aromatic compounds are evolved during pyrolysis or combustion of chlorinated polymers, such as chlorobenzenes (CBzs), chlorophenols (CPhs), chlorobiphenyls (PCBs) and, polychlorodibenzo-p-dioxins and polychlorodibenzofurans (PCDD/Fs) [71]. This could be especially alarming when the process is uncontrolled. Illegal recycling, open burning at landfills or accidental fires involves a serious damage to health and to environment.

Generally, the flue gas treatment systems are complex and expensive, and their technology needs improvement [72]. Most incineration plants have not a cleaning system necessary to eliminate salts from marine debris, and the percentage of ashes generated in this process is relatively high. In addition, several islands, such as Sochung (Korea), have some difficulties to treat marine debris due to long distance between the shore and the plant, causing issues for transport the marine debris [63]. In order to improve the incineration process, a new system has been developed in Korea that can treat up to $100 \mathrm{~kg} / \mathrm{h}$. This system uses activated carbon for the removal of dioxins, slaked lime for the removal of $\mathrm{HCl}$ or SOx and a back filter to remove heavy metals, dioxins and dusts. It has been proved that the concentration of dioxins discharged to the atmosphere by this incineration process of marine debris satisfies the emission limits [56]. The ash generated after the incineration process is less than $5 \%$ of treated marine debris. 


\section{Plans and actions adopted in related to marine debris}

\subsection{Internationally}

290

291

292

293

294

295

296

297

298

299

300

301

302

303

304

305

306

307

308

309

310

311

312

315

313 An important measure that is having good result is the restriction on the use of plastic bags. 314 It is intended that people use only the necessary bags. Consequently, governments decided to

The Ocean Conservancy launched the International Coastal Cleanup (ICC) plan in 1986. In this plan 97 countries and regions participated, and large amount of marine debris was collected [73]. The target of this plan was to obtain information about the type and quantity in which these residues are found in the marine environment. Since 1993, Brazil, Norway, United Kingdom, Chile, Australia, Uruguay and the United States have been performing a marine debris survey program associated to the Convention on the Conservation of Antarctic Marine Living Resources (CCAMLR) [74]. Since 1996, the Environmental Protection Agency (EPA) of the United States has been assessing the state of marine debris in the Gulf of Mexico, using a standardized recording sheet [75]. Taiwan began to make plans related to marine debris collection in 1997, when the government adopted Coastal Environment Cleanup Operation Guidelines [76]. Korea began to develop plans and actions to removed marine debris in 2003 [63]. The Honolulu Strategy was approved in 2011 by the United Nations Environment Program (UNEP). The UNEP suggested that member nations adopt those measures [77].

\subsection{Nationally}

Nowadays, some coastal municipalities in most countries have implemented a number of measures to prevent marine debris to end up in the ocean, such as the payment of rewards to tourists in car parks near sea areas for not littering, compensations to fishing boats that collect marine debris, commercial and recreation fishing fees, penalties for the discharge of polluting substances in the sea, etc. The purpose of these measures is the reduction of waste from entering into the sea. Additionally, the collected money is intended to support the financial and technical development for the installation of waste management plants in fishing boards, recreational crafts and large vessels, as well as funding projects for beaches and coastal waters cleaning. face in new bagging fees instead of allowing supermarkets to provide free bags. Taiwan has 
reduced the consumption of plastic bags on a $58.34 \%$ with this initiative [78]. Other countries, as is the case of France, have banned the use of plastic bags in stores from January 2016.

\section{Suggestions and further changes to reduce marine debris}

Marine debris is a real issue in the oceans around the globe. To fight this problem, government departments could try to improve their advertising and even provide incentives to people who recycle [44].

Education is also important in order to improve the actual condition of oceans and could change the habits of people in an effective way, especially starting during childhood [4]. Education about the importance of recycling and caring for the marine environment must be incorporated into the study programs, and schools should organize activities every year to clean nearby beaches [44]. Further events should also be organized to educate people in how to treat the environment properly after and during leisure activities on nature.

An important part of marine debris is attributed to the fishing industry. It has been suggested that fishermen should follow some guidelines for waste disposal at ports, to use bait containers and implement programs for fishing nets recycling [79].

\section{Conclusions}

It is important to raise awareness among people about the importance of this issue and remind them what is thrown into the sea does not disappear. However, despite efforts at global, remind them that those items abandoned in the sea do not degrade easily and are very detrimental for marine environmental. Marine debris continue to pose a growing threat to the oceans, rivers, seas and coasts around the world, as well as the requirement for waste extraction and treatment of these wastes and the consequent costs that they lead to.

As a consequence, there is an growing need to tackle the issue through more effective laws and regulations enforcement, coordinated and expanded outreach of educational campaigns, and the employment of strong economic instruments such as fines for those who litter in the oceans or coasts and incentives for prevention and waste reduction [3]. 
9. Acknowledgements

343 Support for this work was provided Spanish Ministry of Culture and Sport and by the 344 CTQ2013-41006-R project from the Ministry of Economy and Competitiveness (Spain) and the 345 PROMETEOII/2014/007 project from the Valencian Community Government (Spain). 
[1] Coe JM, Rogers DE. Marine Debris: Sources, Impacts and Solutions. Springer, New York. 1997.

350 [2] Galgani F, Fleet D, Van Franeker J, Katsanevakis S, Maes T, Mouat J, et al. Marine Strategy 351 Framework Directive - Task Group 10 Report Marine Litter. In: Zampoukas, N (Ed), JRC Scientific and Technical Reports European Commission Joint Research Centre, Ispra

2010.

[3] UNEP. Marine Litter: A Global Challenge. Nairobi: UNEP. 2009:232

[4] Derraik JGB. The pollution of the marine environment by plastic debris: a review. Marine Pollution Bulletin. 2002;44:842-52.

357 [5] Gregory MR. Environmental implications of plastic debris in marine settingsentanglement, ingestion, smothering, hangers-on, hitch-hiking and alien invasions. Philosophical Transactions of the Royal Society of London B: Biological Sciences. 2009;364:2013-25.

361 [6] Rochman CM, Manzano C, Hentschel BT, Simonich SLM, Hoh E. Polystyrene Plastic: A 362 Source and Sink for Polycyclic Aromatic Hydrocarbons in the Marine Environment. 363 Environmental Science \& Technology. 2013;47:13976-84.

364 [7] Gaylor MO, Harvey E, Hale RC. House crickets can accumulate polybrominated diphenyl 365 ethers (PBDEs) directly from polyurethane foam common in consumer products. 366 Chemosphere. 2012;86:500-5.

367 [8] Holmes LA, Turner A, Thompson RC. Adsorption of trace metals to plastic resin pellets in the marine environment. Environmental Pollution. 2012;160:42-8.

[9] Mato $\mathrm{Y}$, Isobe T, Takada H, Kanehiro H, Ohtake C, Kaminuma T. Plastic Resin Pellets as a Transport Medium for Toxic Chemicals in the Marine Environment. Environmental Science \& Technology. 2001;35:318-24.

[10] Rochman CM, Hoh E, Hentschel BT, Kaye S. Long-Term Field Measurement of Sorption of Organic Contaminants to Five Types of Plastic Pellets: Implications for Plastic Marine Debris. Environmental Science \& Technology. 2013;47:1646-54.

[11] Teuten EL, Saquing JM, Knappe DRU, Barlaz MA, Jonsson S, Björn A, et al. Transport and release of chemicals from plastics to the environment and to wildlife. Philosophical Transactions of the Royal Society of London B: Biological Sciences. 2009;364:2027-45.

[12] Mouat J, Lopez Lozano R, Bateson H. Economic impacts of marine litter. Kommunenes Internasjonale Miljøorganisasjon (KIMO International), UK. 2010.

[13] Carson HS. The incidence of plastic ingestion by fishes: From the prey's perspective. Marine Pollution Bulletin. 2013;74:170-4.

[14] Baulch S, Perry C. Evaluating the impacts of marine debris on cetaceans. Marine Pollution Bulletin. 2014;80:210-21.

[15] Lazar B, Gračan R. Ingestion of marine debris by loggerhead sea turtles, Caretta caretta, in the Adriatic Sea. Marine Pollution Bulletin. 2011;62:43-7.

[16] Azzarello MY, Van Vleet ES. Marine birds and plastic pollution. Mar Ecol - Prog Ser. 1987;37:295-303.

[17] Ryan PG, Jackson S. The lifespan of ingested plastic particles in seabirds and their effect on digestive efficiency. Marine Pollution Bulletin. 1987;18:217-9.

[18] Laist D. Impacts of Marine Debris: Entanglement of Marine Life in Marine Debris Including a Comprehensive List of Species with Entanglement and Ingestion Records. In: Coe J, Rogers D, editors. Marine Debris: Springer New York; 1997. p. 99-139.

[19] Schrey E, Vauk GJM. Records of entangled gannets (Sula bassana) at Helgoland, German Bight. Marine Pollution Bulletin. 1987;18:350-2. 
[20] Chiappone M, Dienes H, Swanson DW, Miller SL. Impacts of lost fishing gear on coral reef sessile invertebrates in the Florida Keys National Marine Sanctuary. Biological Conservation. 2005;121:221-30.

[21] Takehama S. Estimation of damages to fishing vessels caused by marine debris, based on insurance statistics. Fishing ground environment conservation division fisheries agency, the Government of Japan, Tokyo, Japan. 1990:792-809.

[22] Cheshire AC, Adler E, Barbière J, Cohen Y, Evans S, Jarayabhand S, et al. UNEP/IOC Guidelines on Survey and Monitoring of Marine Litter. UNEP Regional Seas Reports and Studies, No 186; IOC Technical Series No 83: xii + 120 pp. 2009. litter on beaches in the OSPAR region. OSPAR Commission, London. 2007.

[24] Thompson RC, Moore CJ, vom Saal FS, Swan SH. Plastics, the environment and human health: current consensus and future trends. Philosophical Transactions of the Royal Society of London B: Biological Sciences. 2009;364:2153-66.

[25] UNEP-CAR/RCU. Marine Litter in the Wider Caribbean Region: A Regional Overview. United Nations Environment Programme, Nairobi, p 81. 2008.

[26] UNEP. Marine Litter an Analytical Overview. United Nations Environment Programme, Kenya, p. 47. 2005.

[27] Laist DW. Overview of the biological effects of lost and discarded plastic debris in the marine environment. Marine Pollution Bulletin. 1987;18:319-26.

[28] Barnes DKA, Galgani F, Thompson RC, Barlaz M. Accumulation and fragmentation of plastic debris in global environments. Philosophical Transactions of the Royal Society of London B: Biological Sciences. 2009;364:1985-98.

[29] Katsanevakis S. Marine debris, a growing problem: Sources, distribution, composition, and impacts. Marine Pollution: New Research Hofer, TN (Ed) Nova Science Publishers, New York 2008:53-100.

[30] Arthur C, Baker J, Bamford H. Proceedings of the International Research Workshop on the Occurrence, Effects and Fate of Microplastic Marine Debris. NOAA Technical Memorandum NOS-OR\&R-30. 2009.

[31] Andrady AL. Microplastics in the marine environment. Marine Pollution Bulletin. 2011;62:1596-605.

[32] Cole M, Lindeque P, Halsband C, Galloway TS. Microplastics as contaminants in the marine environment: A review. Marine Pollution Bulletin. 2011;62:2588-97.

[33] Gorman M. Environmental Hazards-Marine Pollution. ABC-CLIO Inc, Santa Barbara. 1993. [34] Gregory MR, Ryan PG. Pelagic Plastics and Other Seaborne Persistent Synthetic Debris: A Review of Southern Hemisphere Perspectives. In: Coe J, Rogers D, editors. Marine Debris: Springer New York; 1997. p. 49-66.

[35] Heo N, Hong S, Han G, Hong S, Lee J, Song Y, et al. Distribution of small plastic debris in cross-section and high strandline on Heungnam beach, South Korea. Ocean Sci J. 2013;48:22533.

[36] Hidalgo-Ruz V, Gutow L, Thompson RC, Thiel M. Microplastics in the Marine Environment: A Review of the Methods Used for Identification and Quantification. Environmental Science \& Technology. 2012;46:3060-75.

[37] Martins J, Sobral P. Plastic marine debris on the Portuguese coastline: A matter of size? Marine Pollution Bulletin. 2011;62:2649-53.

[38] Carson HS, Lamson MR, Nakashima D, Toloumu D, Hafner J, Maximenko N, et al. Tracking the sources and sinks of local marine debris in Hawai'i. Marine Environmental Research. 2013;84:76-83.

[39] Lechner A, Keckeis H, Lumesberger-Loisl F, Zens B, Krusch R, Tritthart M, et al. The Danube so colourful: A potpourri of plastic litter outnumbers fish larvae in Europe's second largest river. Environmental Pollution (Barking, Essex : 1987). 2014;188:177-81. 

Modern Gift. In: Whitacre DM, editor. Reviews of Environmental Contamination and 448 Toxicology: Springer New York; 2012. p. 1-44.

449 [41] Cunningham DJ, Wilson SP. Marine Debris on Beaches of the Greater Sydney Region. 450 Journal of Coastal Research. 2003;19:421-30.

451 [42] de Araújo MCB, da Costa MF. Visual diagnosis of solid waste contamination of a tourist 452 beach: Pernambuco, Brazil. Waste Management. 2007;27:833-9.

453 [43] Ivar do Sul JA, Costa MF. Marine debris review for Latin America and the Wider Caribbean 454 Region: From the 1970s until now, and where do we go from here? Marine Pollution Bulletin. 2007;54:1087-104.

[44] Kuo F-J, Huang H-W. Strategy for mitigation of marine debris: Analysis of sources and composition of marine debris in northern Taiwan. Marine Pollution Bulletin. 2014;83:70-8. stock of marine debris in South Korea for management purposes. Marine Pollution Bulletin. 2014;86:505-11.

[46] NAS. Marine litter. In: Assessing Potential Ocean Pollutants A report on the study of assessing potential ocean pollutants to the Ocean Affairs Board, Commission of the Natural Resources, National Research Council, National Academy of Sciences, Washington, DC. 1975:465.

[47] Morris RJ. Floating plastic debris in the Mediterranean. Marine Pollution Bulletin. 1980;11:125.

[48] Thiel M, Hinojosa IA, Miranda L, Pantoja JF, Rivadeneira MM, Vásquez N. Anthropogenic marine debris in the coastal environment: A multi-year comparison between coastal waters and local shores. Marine Pollution Bulletin. 2013;71:307-16.

[49] Goto T, Shibata H. Changes in abundance and composition of anthropogenic marine debris on the continental slope off the Pacific coast of northern Japan, after the March 2011 Tohoku earthquake. Marine Pollution Bulletin. 2015;95:234-41.

[50] Ryan PG. A simple technique for counting marine debris at sea reveals steep litter gradients between the Straits of Malacca and the Bay of Bengal. Marine Pollution Bulletin. 2013;69:128-36.

[51] Duhec AV, Jeanne RF, Maximenko N, Hafner J. Composition and potential origin of marine debris stranded in the Western Indian Ocean on remote Alphonse Island, Seychelles. Marine Pollution Bulletin.

[52] Duhec AV, Jeanne RF, Maximenko N, Hafner J. Composition and potential origin of marine debris stranded in the Western Indian Ocean on remote Alphonse Island, Seychelles. Marine Pollution Bulletin. 2015;96:76-86.

[53] Rillig MC. Microplastic in Terrestrial Ecosystems and the Soil? Environmental Science \& Technology. 2012;46:6453-4.

[54] Koelmans AA, Gouin T, Thompson R, Wallace N, Arthur C. Plastics in the marine environment. Environmental Toxicology and Chemistry. 2014;33:5-10.

[55] Jambeck JR, Geyer R, Wilcox C, Siegler TR, Perryman M, Andrady A, et al. Plastic waste inputs from land into the ocean. Science. 2015;347:768-71.

[56] MOMAF MoMAaF-. National report on research and Development on Comprehensive Disposal System for Marine Debris, Korea. 1999-2007.

[57] Ha YG, Cho KD, Kim SW. The cost-sharing system for managing (the marine litter by agreement among the administrative organization of around the capital area in Korea), The 1st NOWPAP Workshop on Marine Litter, Incheon, Korea. 2006.

[58] Donohue MJ, Boland RC, Sramek CM, Antonelis GA. Derelict Fishing Gear in the Northwestern Hawaiian Islands: Diving Surveys and Debris Removal in 1999 Confirm Threat to Coral Reef Ecosystems. Marine Pollution Bulletin. 2001;42:1301-12. 

Mediterranean. Marine Pollution Bulletin. 1995;30:22-4.

498 [60] Stefatos A, Charalampakis M, Papatheodorou G, Ferentinos G. Marine Debris on the 499 Seafloor of the Mediterranean Sea: Examples from Two Enclosed Gulfs in Western Greece. 500 Marine Pollution Bulletin. 1999;38:389-93.

501 [61] Galgani F, Leaute JP, Moguedet P, Souplet A, Verin Y, Carpentier A, et al. Litter on the Sea Floor Along European Coasts. Marine Pollution Bulletin. 2000;40:516-27.

[62] Kang WS, et al., al. e. Executable Plan of Removal and Treatment for Marine Debris in Regional Sea Waters in Incheon Area, KRISO/KORDI Project Report. 2001.

[63] Jung R-T, Sung HG, Chun T-B, Keel S-I. Practical engineering approaches and infrastructure to address the problem of marine debris in Korea. Marine Pollution Bulletin. 2010;60:1523-32. [64] Takada H. Call for pellets! International Pellet Watch Global Monitoring of POPs using beached plastic resin pellets. Marine Pollution Bulletin. 2006;52:1547-8. [65] Lee H, Shim WJ, Kwon JH. Sorption capacity of plastic debris for hydrophobic organic chemicals. Sci Total Environ. 2014;470-471:1545-52.

[66] Rochman CM, Manzano C, Hentschel BT, Simonich SLM, Hoh E. Polystyrene plastic: A source and sink for polycyclic aromatic hydrocarbons in the marine environment. Environ Sci Technol. 2013;47:13976-84.

[67] Fisner M, Taniguchi S, Majer AP, Bícego MC, Turra A. Concentration and composition of polycyclic aromatic hydrocarbons (PAHs) in plastic pellets: Implications for small-scale diagnostic and environmental monitoring. Marine Pollution Bulletin. 2013;76:349-54.

[68] Krüger O, Kalbe U, Meißner K, Sobottka S. Sorption effects interfering with the analysis of polycyclic aromatic hydrocarbons (PAH) in aqueous samples. Talanta. 2014;122:151-6.

[69] Jung RT, Lee EJ, Kim SD, Chun TB. State-of-the-art of treatment and management of waste FRP vessels and a new suggestion of environmentalfriendly framework. Journal of Ships and Ocean Engineering. 2007;44:125-33.

[70] Hagstrom B, Hampton RN, Helmesjo B, Hjertberg T. Disposal of cables at the "end of life"; some of the environmental considerations. Electrical Insulation Magazine, IEEE. 2006;22:21-30. [71] Aracil I, Font R, Conesa JA. Semivolatile and volatile compounds from the pyrolysis and combustion of polyvinyl chloride. J Anal Appl Pyrolysis. 2005;74:465-78.

[72] Asian Development Bank. Report and Recommendation of the President to the Board of Directors-Proposed Loan and technical Assistance Municipal Waste to Energy Project. People's Republic of China.

$529 ; 2009$.

530 [73] The Ocean Conservancy. 2012 Ocean trash index. The Ocean Conservancy; 2013.

531 [74] Edyvane KS, Dalgetty A, Hone PW, Higham JS, Wace NM. Long-term marine litter 532 monitoring in the remote Great Australian Bight, South Australia. Marine Pollution Bulletin. 533 2004;48:1060-75.

534 [75] Sheavly SB. National marine debris monitoring program-lessons learned. U.S. 535 Environmental Protection Agency, Oceans and Coastal Protection Division, Marine Pollution 536 Control Branch. 2010.

537 [76] Environment Protection Administration. Coastal Environment Cleanup Operation 538 Guidelines, EPA, Taiwan (Ed.), No. 35666. EPA, Taipei, Taiwan; 1997.

539 [77] UNEP. The Honolulu Strategy: a global framework for prevention and management of 540 marine debris. 2011.

541 [78] Environment Protection Administration Executive Yuan. Introduction to Resources 542 Recycling (in Chinese). EPA.; 2014.

543 [79] Jones MM. Fishing debris in the Australian marine environment. Marine Pollution Bulletin. $544 \quad 1995 ; 30: 25-33$. 
[80] Suaria G, Aliani S. Floating debris in the Mediterranean Sea. Marine Pollution Bulletin. 546 2014;86:494-504.

547 [81] Viehman S, Vander Pluym JL, Schellinger J. Characterization of marine debris in North 548 Carolina salt marshes. Marine Pollution Bulletin. 2011;62:2771-9.

549 [82] Ribic CA, Sheavly SB, Klavitter J. Baseline for beached marine debris on Sand Island, 550 Midway Atoll. Marine Pollution Bulletin. 2012;64:1726-9.

551 [83] Eriksson C, Burton H, Fitch S, Schulz M, van den Hoff J. Daily accumulation rates of marine debris on sub-Antarctic island beaches. Marine Pollution Bulletin. 2013;66:199-208.

[84] Pieper C, Ventura MA, Martins A, Cunha RT. Beach debris in the Azores (NE Atlantic): Faial Island as a first case study. Marine Pollution Bulletin.

[85] Zhou P, Huang C, Fang H, Cai W, Li D, Li X, et al. The abundance, composition and sources of marine debris in coastal seawaters or beaches around the northern South China Sea (China). Marine Pollution Bulletin. 2011;62:1998-2007.

[86] Hong S, Lee J, Kang D, Choi H-W, Ko S-H. Quantities, composition, and sources of beach debris in Korea from the results of nationwide monitoring. Marine Pollution Bulletin. 2014;84:27-34.

[87] Silva MLd, Araújo FVd, Castro RO, Sales AS. Spatial-temporal analysis of marine debris on beaches of Niterói, RJ, Brazil: Itaipu and Itacoatiara. Marine Pollution Bulletin. 2015;92:233-6.

[88] Madzena A, Lasiak T. Spatial and temporal variations in beach litter on the Transkei coast of South Africa. Marine Pollution Bulletin. 1997;34:900-7.

[89] Eryaşar AR, Özbilgin H, Gücü AC, Sakınan S. Marine debris in bottom trawl catches and their effects on the selectivity grids in the north eastern Mediterranean. Marine Pollution Bulletin. 2014;81:80-4.

[90] Van Cauwenberghe L, Claessens M, Vandegehuchte MB, Mees J, Janssen CR. Assessment of marine debris on the Belgian Continental Shelf. Marine Pollution Bulletin. 2013;73:161-9. [91] Koutsodendris A, Papatheodorou G, Kougiourouki O, Georgiadis M. Benthic marine litter in four Gulfs in Greece, Eastern Mediterranean; abundance, composition and source identification. Estuarine, Coastal and Shelf Science. 2008;77:501-12.

[92] Gasperi J, Dris R, Bonin T, Rocher V, Tassin B. Assessment of floating plastic debris in surface water along the Seine River. Environmental Pollution. 2014;195:163-6.

[93] Ryan PG, Bouwman H, Moloney CL, Yuyama M, Takada H. Long-term decreases in persistent organic pollutants in South African coastal waters detected from beached polyethylene pellets. Marine Pollution Bulletin. 2012;64:2756-60.

[94] Browne MA, Galloway TS, Thompson RC. Spatial Patterns of Plastic Debris along Estuarine Shorelines. Environmental Science \& Technology. 2010;44:3404-9.

[95] Browne MA, Crump P, Niven SJ, Teuten E, Tonkin A, Galloway T, et al. Accumulation of Microplastic on Shorelines Woldwide: Sources and Sinks. Environmental Science \& Technology. 2011;45:9175-9.

[96] Yeo BG, Takada H, Taylor H, Ito M, Hosoda J, Allinson M, et al. POPs monitoring in Australia and New Zealand using plastic resin pellets, and International Pellet Watch as a tool for education and raising public awareness on plastic debris and POPs. Marine Pollution Bulletin.

[97] Heskett M, Takada H, Yamashita R, Yuyama M, Ito M, Geok YB, et al. Measurement of persistent organic pollutants (POPs) in plastic resin pellets from remote islands: Toward establishment of background concentrations for International Pellet Watch. Marine Pollution Bulletin. 2012;64:445-8.

[98] Ogata Y, Takada H, Mizukawa K, Hirai H, Iwasa S, Endo S, et al. International Pellet Watch: Global monitoring of persistent organic pollutants (POPs) in coastal waters. 1. Initial phase data on PCBs, DDTs, and HCHs. Marine Pollution Bulletin. 2009;58:1437-46. 
594 [99] Gauquie J, Devriese L, Robbens J, De Witte B. A qualitative screening and quantitative 595 measurement of organic contaminants on different types of marine plastic debris. 596 Chemosphere. 2015;138:348-56.

597 [100] Hirai H, Takada H, Ogata Y, Yamashita R, Mizukawa K, Saha M, et al. Organic 598 micropollutants in marine plastics debris from the open ocean and remote and urban beaches. 599 Marine Pollution Bulletin. 2011;62:1683-92.

600 [101] Van A, Rochman CM, Flores EM, Hill KL, Vargas E, Vargas SA, et al. Persistent organic 601 pollutants in plastic marine debris found on beaches in San Diego, California. Chemosphere. $602 \quad 2012 ; 86: 258-63$.

603

604

605

LIST OF TABLES

606 Table 1. Proportion of plastics (per number of items collected) in marine debris.

607 Table 2. Composition of plastics recovered from the marine environment.

608 Table 3. POPs contained in different marine litter around the world.

609

610 LIST OF FIGURES

611 Figure 1. Typical lifecycle of marine debris

612

613

614 


\begin{tabular}{|c|c|c|c|}
\hline Locality & Litter type & $\begin{array}{l}\text { Percentage of debris items represented } \\
\text { by plastics }\end{array}$ & Reference \\
\hline $\begin{array}{l}\text { Central and Western part of the } \\
\text { Mediterranean Sea }\end{array}$ & Floating debris & 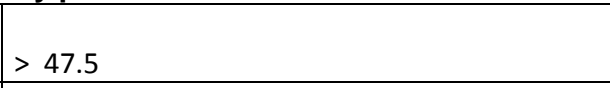 & {$[80]$} \\
\hline European coasts & Sea floor & $>70$ & {$[61]$} \\
\hline $\begin{array}{l}\text { Salt marshes in Carteret Country (North } \\
\text { Carolina) }\end{array}$ & Floating debris & 45,6 & {$[81]$} \\
\hline Sand Island, Midway Atoll & Beach & 65,7 & {$[82]$} \\
\hline Two Sub-antartic Island beaches & Beach & $94-95$ & {$[83]$} \\
\hline Azores (NE Atlantic): Faial Island & Beach & 93,14 & {$[84]$} \\
\hline \multirow{3}{*}{ Northern South China Sea } & Floating debris & 44,9 & \multirow{3}{*}{ [85] } \\
\hline & Sea floor & 47 & \\
\hline & Beach & 42 & \\
\hline 20 Korea beaches & Beach & 66,7 & {$[86]$} \\
\hline 2 beaches of Niterói, RJ, Brazil & Beach & 52 & {$[87]$} \\
\hline Cliffwood Beach, New Jersey & Beach & 42,5 & {$[88]$} \\
\hline North Eastern Mediterranean & Sea floor & 73 & {$[89]$} \\
\hline \multirow{3}{*}{ Belgian coastal waters } & Beach & 95,5 & \multirow{3}{*}{ [90] } \\
\hline & Floating debris & 95,7 & \\
\hline & Sea floor & 95,7 & \\
\hline W\&S Greece & Water column, sea floor & 55,9 & {$[91]$} \\
\hline *Baltic Sea, (4 countries) & Beach, floating debris, sea floor & $<60$ & {$[3]$} \\
\hline *Black Sea ( 2 country) & Beach, floating debris, sea floor & $>65$ & {$[3]$} \\
\hline${ }^{*}$ Caspian Sea ( 1 country) & Beach, floating debris, sea floor & $>60$ & {$[3]$} \\
\hline *East Asian Seas ( 8 countries) & Beach, floating debris, sea floor & $>64$ & {$[3]$} \\
\hline *Eastern Africa (4 countries) & Beach, floating debris, sea floor & $>58$ & {$[3]$} \\
\hline *Mediterranean (11 countries) & Beach, floating debris, sea floor & $>56$ & {$[3]$} \\
\hline *Northeast Atlantic (11 countries) & Beach, floating debris, sea floor & 75,01 & {$[3]$} \\
\hline *Northwest Pacific ( 3 countries) & Beach, floating debris, sea floor & $>60$ & {$[3]$} \\
\hline *Red Sea and Gulf of Aden ( 2 countries) & Beach, floating debris, sea floor & $>55$ & {$[3]$} \\
\hline *South Pacific ( 5 countries) & Beach, floating debris, sea floor & $>50$ & {$[3]$} \\
\hline *South Asian Seas ( 3 countries) & Beach, floating debris, sea floor & $>65$ & {$[3]$} \\
\hline *Wider Caribbean ( 21 countries) & Beach, floating debris, sea floor & $>63$ & [3] \\
\hline
\end{tabular}




\begin{tabular}{|c|c|c|c|c|c|c|c|}
\hline \multirow[b]{2}{*}{ LOCALITY } & \multirow[b]{2}{*}{ LITTER TYPE } & \multicolumn{5}{|c|}{$\begin{array}{c}\text { Percentage of debris items represented by } \\
\text { plastics }\end{array}$} & \multirow[b]{2}{*}{ Reference } \\
\hline & & CA & PE & PP & PET & PS & \\
\hline Seine River & Surface water & - & 26 & 35,2 & 20,7 & 10,8 & {$[92]$} \\
\hline Sand Island, Midway Atoll & Surface water & - & 56 & 30 & - & - & {$[82]$} \\
\hline 3 South African beaches & Beach & - & 82 & 11 & - & - & [93] \\
\hline $\begin{array}{l}\text { sandy beaches in Australia, Oman, } \\
\text { United Arab Emirates, Chile, } \\
\text { Philippines, Azores, USA, South Africa, } \\
\text { Mozambique and the U.K. }\end{array}$ & Beach & - & 6 & 7 & 56 & - & {$[94,95]$} \\
\hline *Baltic Sea, (4 countries) & Beach, floating debris, sea floor & 37,4 & $<20$ & $<17$ & 6,5 & - & {$[3]$} \\
\hline *Black Sea ( 2 country) & Beach, floating debris, sea floor & 22,4 & $<22$ & $<10$ & 20,9 & 3,3 & {$[3]$} \\
\hline *Caspian Sea (1 country) & Beach, floating debris, sea floor & - & $<50$ & $<50$ & 14,6 & - & {$[3]$} \\
\hline *East Asian Seas (8 countries) & Beach, floating debris, sea floor & 17,5 & $<40$ & $<25$ & 6,3 & - & {$[3]$} \\
\hline *Eastern Africa (4 countries) & Beach, floating debris, sea floor & 6,7 & $<43$ & $<23$ & 10,2 & - & {$[3]$} \\
\hline *Mediterranean (11 countries) & Beach, floating debris, sea floor & 29,1 & $<20$ & $<12$ & 4,1 & - & {$[3]$} \\
\hline *Northeast Atlantic (11 countries) & Beach, floating debris, sea floor & 16 & $<30$ & $<26$ & 7,9 & 4,8 & {$[3]$} \\
\hline *Northwest Pacific (3 countries) & Beach, floating debris, sea floor & 24,3 & $<31$ & $<24$ & 3,4 & 2,7 & {$[3]$} \\
\hline $\begin{array}{l}\text { * Red Sea and Gulf of Aden ( } 2 \\
\text { countries) }\end{array}$ & Beach, floating debris, sea floor & 9,3 & $<30$ & $<15$ & 4,6 & 13,2 & {$[3]$} \\
\hline *South Pacific (5 countries) & Beach, floating debris, sea floor & 5,2 & $<35$ & $<27$ & 8,1 & 3,0 & [3] \\
\hline *South Asian Seas (3 countries) & Beach, floating debris, sea floor & 10,9 & $<45$ & $<15$ & 3,6 & - & {$[3]$} \\
\hline *Wider Caribbean (21 countries) & Beach, floating debris, sea floor & 2,9 & $<32$ & $<20$ & 16,8 & 5,7 & [3] \\
\hline
\end{tabular}




\begin{tabular}{|c|c|c|c|c|c|c|}
\hline \multirow{2}{*}{ Location } & \multirow{2}{*}{ Plastic sample } & \multicolumn{4}{|c|}{ Contaminants (ng/g-pellet) } & \multirow{2}{*}{ Reference } \\
\hline & & PCBs & HCHs & DDTs & PAHs & \\
\hline Australia (17 locations) & \multirow{2}{*}{ PE and PP pellets } & $0.1-294$ & n.a. -20.71 & $0.52-421$ & - & \multirow[b]{2}{*}{ [96] } \\
\hline New Zeland's North Island (6 locations) & & $0.25-157$ & n.a. - 28.94 & $3.17-47.03$ & - & \\
\hline Canary (Fuerteventura, El Cotillo)b & \multirow{8}{*}{ Plastic resin pellets } & 9 & 0,6 & 4,1 & - & \multirow{8}{*}[97]{} \\
\hline Oahu (Kahuku Beach) ${ }^{a}$ & & 0,7 & 0,4 & 0,8 & - & \\
\hline Oahu (Wawamalu beach) ${ }^{a}$ & & 0,1 & 1,6 & 0,7 & - & \\
\hline Oahu (Waimanalo Bay) ${ }^{a}$ & & 1,5 & 0,2 & 0,9 & - & \\
\hline Hawaii (Kamilo beach) ${ }^{a}$ & & 9,9 & 0,6 & 3,4 & - & \\
\hline Barbados (Martins Bay) ${ }^{a}$ & & 1,7 & 0,8 & 3,1 & - & \\
\hline Cocos (Bob's Folly Beach) ${ }^{a}$ & & 6,5 & 1,7 & 3,4 & - & \\
\hline St. Helena (Sandy Bay) ${ }^{a}$ & & 7 & 19,3 & 3,4 & - & \\
\hline Kehoe Beach, CA (USA) & \multirow{16}{*}{ Polyethylene pellets } & 86 & $0.15-0.94$ & 95,7 & - & \multirow{16}{*}{ [98] } \\
\hline Seal Beach, CA (USA) & & 48 & $0.25-0.45$ & 37,2 & - & \\
\hline Dungeness Spit, WA (USA) & & 32 & $0.29-0.35$ & 5,09 & - & \\
\hline Quincy Bay, MA (USA) & & 416 & 0,57 & 6,83 & - & \\
\hline Costa Nova (Portugal) & & 27 & $0.55-0.56$ & 1,69 & - & \\
\hline Forth Estuary (UK) & & 87 & $0.52-0.92$ & 2,16 & - & \\
\hline Kato Achaia (Greece) & & 5 & 1,04 & 9,41 & - & \\
\hline Izmir (Turkey) & & 53 & $0.83-1.12$ & 27,6 & - & \\
\hline Mumbai (India) & & 43 & $1.77-2.20$ & 9,58 & - & \\
\hline Chennai (India) & & 141 & 3,24 & 29,8 & - & \\
\hline Rayong (Thailand) & & 6 & $0.17-0.48$ & 25,9 & - & \\
\hline Jakarta Bay (Indonesia) & & 16 & 1,09 & 13,7 & - & \\
\hline Minh Chau Island (Vietnam) & & 26 & $1.07-1.23$ & 163 & - & \\
\hline Foul Bay (Australia) & & 16 & $0.14-0.19$ & 6,69 & - & \\
\hline Bay of Maputo (Mozambique) & & 9 & $36.4-37.1$ & 4,49 & - & \\
\hline South Durban (South Africa) & & 41 & 33,9 & 2,43 & - & \\
\hline Belgian Coast & $\begin{array}{l}\text { Plastic litter and beached } \\
\text { pellets }\end{array}$ & $31-236$ & - & - & $1076-3007$ & [99] \\
\hline $\begin{array}{l}\text { central pacific gyre, Pacific Ocean and Caribbean Sea, } \\
\text { remote beaches at Marbella Beach and Thinh Long, }\end{array}$ & PE and PP plastic fragments & $1-436$ & - & $0-198$ & $0-9297$ & {$[100]$} \\
\hline
\end{tabular}


Tonking Bay and urban beaches at Odaiba, Kugenuma and Seal Beach

San Diego, California (8 beaches)

n.a. $\rightarrow$ Not available

${ }^{a} \rightarrow$ median of five pools

625 


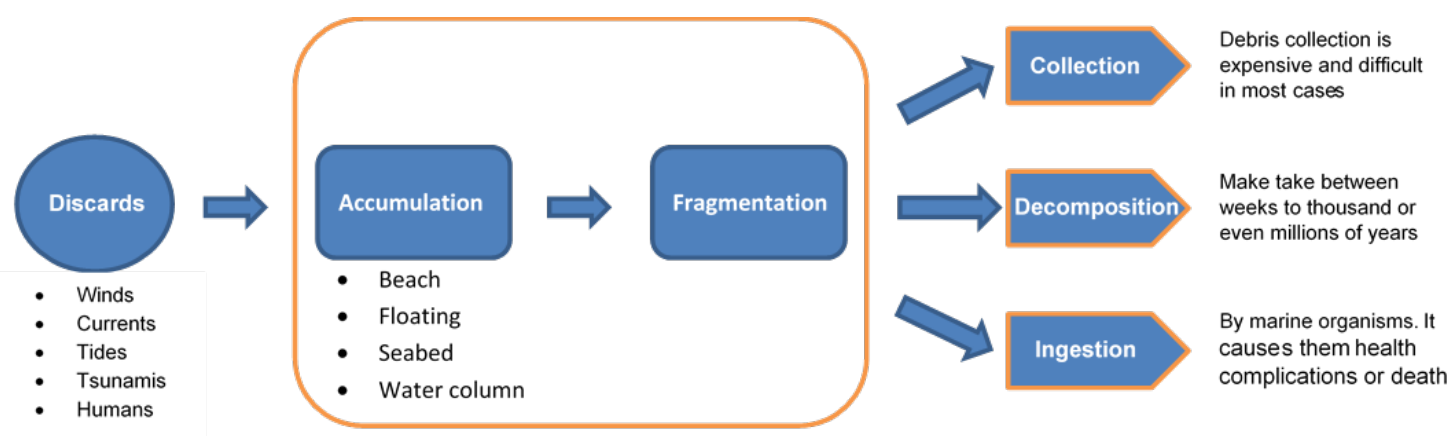

628

Figure 1. Typical lifecycle of marine debris 